\title{
Allometric relationship between body mass and aerobic metabolism in zebrafish Danio rerio
}

\author{
Lucas Julie ${ }^{1,2,{ }^{*}}$, Schouman A. ${ }^{1}$, Lyphout Laura ${ }^{2}$, Cousin Xavier ${ }^{2,3}$, Lefrancois Christelle ${ }^{1}$
}

1 Inst Littoral \& Environm, UMR Littoral Environm Soc LIENSs 7266, F-17000 La Rochelle, France.

2 IFREMER, F-17137 Lhoumeau, France.

3 Inra, LPGP, F-35042 Rennes, France.

* Corresponding author : Julie Lucas, email address : julie.lucas@univ-Ir.fr

\begin{abstract}
:
The relationship between body mass $(\mathrm{M})$ and metabolic rate was investigated through the assessment of active (RA) and standard (RS) metabolic rate at different life stages in zebrafish Danio rerio (5 day-old larvae, 2month-old juveniles and 6 month-old adults). Scaling exponents and constants were assessed for standard $(R S=0.273 \mathrm{M0} \cdot 965 \mathrm{in} \mathrm{mgO} 2 \mathrm{~g}-1 \mathrm{~h}-1)$ and active metabolic rate $(\mathrm{RA}=0.799 \mathrm{M0} \cdot 926 \mathrm{in} \mathrm{mgO2}$ g-1 $h-1)$. These data provide the basis for further experiments regarding the effects of environmental factors on aerobic metabolism throughout the life cycle of this species.
\end{abstract}

Keywords : active metabolic rate, static respirometry, allometric scaling exponent, standard metabolic rate 
Active metabolic rate $\left(R_{\mathrm{A}}\right)$ is the maximal aerobic metabolic rate of an organism in a highly active state and standard metabolic rate $\left(R_{\mathrm{S}}\right)$ isthe minimal metabolic rate necessary for supporting maintenance activities (e.g. ventilation) measured in resting, starved and nonmaturing individual (Fry, 1947; Brett, 1964). Aerobic metabolic scope $\left(R_{\mathrm{AS}}\right)$ is the difference between $R_{\mathrm{A}}$ and $R_{\mathrm{S}}$ and represents the capacity of an organism to provide oxygen to sustain energy demanding activities (Fry, 1947). $R_{\mathrm{AS}}$ can be influenced by a set of environmental parameters such as temperature, oxygen andsalinity (Shurmann\&Steffensen, 1997; Lefrançois\&Claireaux, 2003; Johansen \& Jones, 2011). Ithas therefore been used in many studies to assess the influence of environmental factors on metabolic performance and energydemanding activitiesin various fish species (Fry, 1971; Priede, 1985; Claireaux\&Lefrançois, 2007).It has been demonstrated, in many species however, thatintrinsic parameters such as ontogeny and body size can also influence metabolism independently of any effects of environmental conditions (Clark \& Johnston, 1999; Bokma, 2004;Killen, 2007, 2010; Moran \& Wells, 2007)

ZebrafishDaniorerio(Hamilton 1822) is a small teleost species whose biological characteristics make it suitable for experimental studies (e.g. small size, easy breeding, high fecundity; Miklosi\& Andrew, 2006; Lawrence, 2007). Its short life cycle and rapid development also facilitate investigations regarding the effects of environmental factors on different lifestages. In the last two decades,some studies have been publishedregarding the metabolic performance ofthe D.rerioexposed to various environmental constraints (Plaut\& Gordon, 1994; Plaut, 2000; Marit\& Weber, 2011, 2012). Despite the increasing interest in D.rerio, only the studies of Barrionuevo\&Burggren (1999) and Burggren (2005) investigated how body mass influenced metabolism, although they did not establish the regression describing this relationship.The aim of the present study was therefore to investigate the allometricrelationship between body mass and metabolic rate in D.rerio, and derive the 
species-specific scaling exponent. This was achieved by measuring $R_{\mathrm{A}}$ and $R_{\mathrm{S}}$ atthree different life stages.

Tenbroodstock couples (wild-type Tuebingenstrain, $T U$ ) werereared together in a 101 tank. Spawnings were obtained from these couples each week over two month. In order to avoid any bias due to familial characteristics, at least 5 spawns were mixed. Then, 100 larvae were randomly selected and reared to be tested at three different life stages: (i) larvae, 5 days post fertilization, (ii) $60 \mathrm{dpf}$ juveniles and (iii) 5 months old adults. From 2 weeks onwards, fish were kept in groups of 10 individuals in 31 aquaria with system water prepared as a mix of reverse-osmosis treated and tap water (both being filtered through sediment and activated charcoal filters) to obtain a water with constant conductivity of $300 \mu \mathrm{S}$. Fish were reared at a constant temperature of $28{ }^{\circ} \mathrm{C}$ under artificial light with a constant photoperiod of $14 \mathrm{~h}: 10 \mathrm{~h}$ (L:D) and were fed with dry food (Inicio plus, Biomar, France, http://www.biomar.com) and brine shrimp (Océan Nutrition Europe BVBA, Belgium, http://www.oceannutrition.eu) in the morning and afternoon, respectively. Fish were fasted $24 \mathrm{~h}$ prior to the experiments.

To assess their metabolic rate, fish were placed into circular size-adapted respirometers. For larvae, the set-up consisted of 4independent glass micro respirometer chambers (diameter $d=$ $1.12 \mathrm{~cm}$, volume $V=0.985 .10^{-3} 1$; Loligo systems, Denmark). For the two other life stages, 8 larger respirometers were run simultaneously $(d=3.75 \mathrm{~cm}, V=0.0611$ and $7.50 \mathrm{~cm}, 0.1791$ for juveniles and adults respectively).Respirometers were submerged into buffer tanks (depth $\mathrm{x}$ length $\mathrm{x}$ height: 10x20x31cm for larvae, 10x75x75xcmfor juveniles and adults) and filled with temperature-controlled, oxygenated system water as above. Flush pumps controlled the water supply in each respirometer. Each flush pump was controlled by a timer, allowing intermittent flow respirometry (Steffensen, 1989) where phases of oxygen renewal alternated with phases of oxygen consumption measurements with a period of 15:15min for larvae and 
30:30 min for both juvenilesand adults. In addition, the set-up was completed by amultichannel peristaltic pump was used to mix the water within each respirometer. Each respirometer was equipped with a fiber optic sensor (PreSens) connected to a multichannel oxygen measuring system (OXY 4 mini, PreSens)to record dissolved oxygen levels. Optic fibers were calibrated at $0 \%$ and $100 \%$ of air saturation at a temperature of $28^{\circ} \mathrm{C}$. A factor of conversion based on oxygen solubility into water was used to convert oxygen data from percentage saturation to $\mathrm{mgO}_{2} \cdot \mathrm{l}^{-1}$ (i.e. $100 \%$ was equivalent to $7.94 \mathrm{mgO}_{2} \cdot 1^{-1}$ for a $28^{\circ} \mathrm{C}$ temperature and a 0 salinity).Oxygen saturation was recorded every five seconds with the program Oxyview (PreSens).

Larvae were tested in groups of 10 individuals per chamber. Juveniles and adults were tested individually; each fish was only tested once. Each experimental trial comprised two consecutive steps. First,to assess $R_{\mathrm{A}}$, fish metabolism was increased through chasing (Schurmann\&Steffensen, 1997; Lefrançois\&Claireaux, 2003; Jourdan-Pineauet al., 2010; Cannas et al., 2013, Clark et al., 2012). Each group of larvae or individual fish was transferred from the rearing aquaria to a 6-7 $\mathrm{ml}$ Petri dish or one liter tank respectively, where they were chased with a stick. When exhausted (i.e. did not respond to stimulation), they were transferred in respirometers to measure oxygen consumption over $20 \mathrm{~min}$. After this first measurement of oxygen consumption, a second one was performed to confirm the accuracy of the $R A$ assessment. To do that fish were chased again inside the respirometer and their oxygen consumptionmeasured for a new period of $20 \mathrm{~min}$.To estimate $R_{\mathrm{S}}$, fish were left undisturbed in the respirometerfor $48 \mathrm{~h}$, during which oxygen consumptionwas regularly and automatically measured. After the $48 \mathrm{~h}$ period of measurements, the fish were removed from the respirometers and anesthetized with benzocaïne at a concentration of $50 \mathrm{mg} .1^{-1}$. The wet body mass of each individual was determined, as well as the standard length $L_{\mathrm{S}}$ of juveniles and adults: (a) larvae, $5 \mathrm{dpf}$ ( $n=11$ groups of 10 larvae; mean \pm S.E., mass, $M=0.245 .10^{-3} \pm 0.036 .10^{-}$ 
${ }^{3} \mathrm{~g}$ ), (b) $60 \mathrm{dpf}$ juveniles $\left(n=14, M=0.097 \pm 0.035 \mathrm{~g}, L_{\mathrm{S}}=18.5 \pm 2.2 \mathrm{~mm}\right)$ and (c) 5 months

124 adults $\left(n=22, M=0.326 \pm 0.103 \mathrm{~g}, L_{S}=26.9 \pm 1.9 \mathrm{~mm}\right)$.

125

126 A blank measurement without fish was performed before and after each trial, to quantify

127 background respiration.Linear change is assumed in background oxygen consumptionover the

128 48h-experimental trial and subtracted the calculated background from the corresponding total

129 oxygen consumptionmeasured.

130 The non specific aerobic metabolic rate (or oxygen consumption $\mathrm{MO}_{2}$ in $\mathrm{mgO}_{2} . \mathrm{h}^{1}$ ) was

131 calculated according to the following formula:

132

134

135

136

138

140

141

142

143 The non specific aerobic metabolic rate of organisms typically increases with body mass

144 according to the allometric equation:

145

146

$R=\mathrm{a} M^{\mathrm{b}}$ equation (2) 
148 where $R$ is the metabolic rate $\left(R_{\mathrm{S}}\right.$ or $R_{\mathrm{A}}$ in $\left.\mathrm{mgO}_{2} \cdot \mathrm{h}^{-1}\right)$, a is the species-specific scaling constant

149 (or proportionality constant), $M$ is the body mass (in $\mathrm{g}$ ), and $\mathrm{b}$ is the scaling exponent. This 150 equation is a power function, where the value of $b$ provides information on how the variable 151 of interest changes with body size.

152 Equation (2) can be linearized with a log transformation:

153

154

155

156

157

158

159

160

167 For $R_{\mathrm{S}}$, scaling factor $\mathrm{a}_{\mathrm{RS}}$ and scaling exponent $\mathrm{b}_{\mathrm{RS}}$ was $0.273 \pm 0.038$ ( \pm S.E.) and

$1680.965 \pm 0.015$, respectively when the three life stages were considered. These constantswere $1690.276 \pm 0.084$ and $0.969 \pm 0.110$, respectively, when only juveniles and adults were taken into consideration. These values did not differ significantly for either constant(Student's t-test,

$171 \mathrm{t}_{1.82}=-0.00127, P>0.05 ;$ Student's $\mathrm{t}$-test, $\mathrm{t}_{1.81}=0.00068, P>0.05$, respectively). The same 172 pattern was observed for $R_{\mathrm{A}}$. Scaling factors $\left(\mathrm{a}_{\mathrm{RA}(\mathrm{L}+\mathrm{J}+\mathrm{A})}=0.799 \pm 0.024\right.$ and 
$\left.173 \mathrm{a}_{\mathrm{RA}(\mathrm{J}+\mathrm{A})}=0.809 \pm 0.051\right)$ as well as scaling exponents $\left(\mathrm{b}_{\mathrm{RA}(\mathrm{L}+\mathrm{J}+\mathrm{A})}=0.926 \pm 0.009\right.$ and

$\left.174 b_{\mathrm{RA}(\mathrm{J}+\mathrm{A})}=0.931 \pm 0.068\right)$ did not differ significantly whether larvae were considered or not 175 (Student's t-test, for $\mathrm{a}_{\mathrm{RA}}: \mathrm{t}_{1.81}=0.01270, P>0.05$; for $\mathrm{b}_{\mathrm{RA}}: \mathrm{t}_{1.81}=0.00596, P>0.05$ ). Data for

176 "resting metabolic rate" of D. rerio at $28^{\circ} \mathrm{C}$, reported byBarrionuevo\&Burggren (1999) and

177 Burggren (2005) and converted to $\mathrm{mgO}_{2} \cdot \mathrm{h}^{-1}$, were consistent with $R_{\mathrm{S}}$ values measured in the

178 current study (Fig. 1A). It appears that their data fit with standard metabolic rate regression.

179

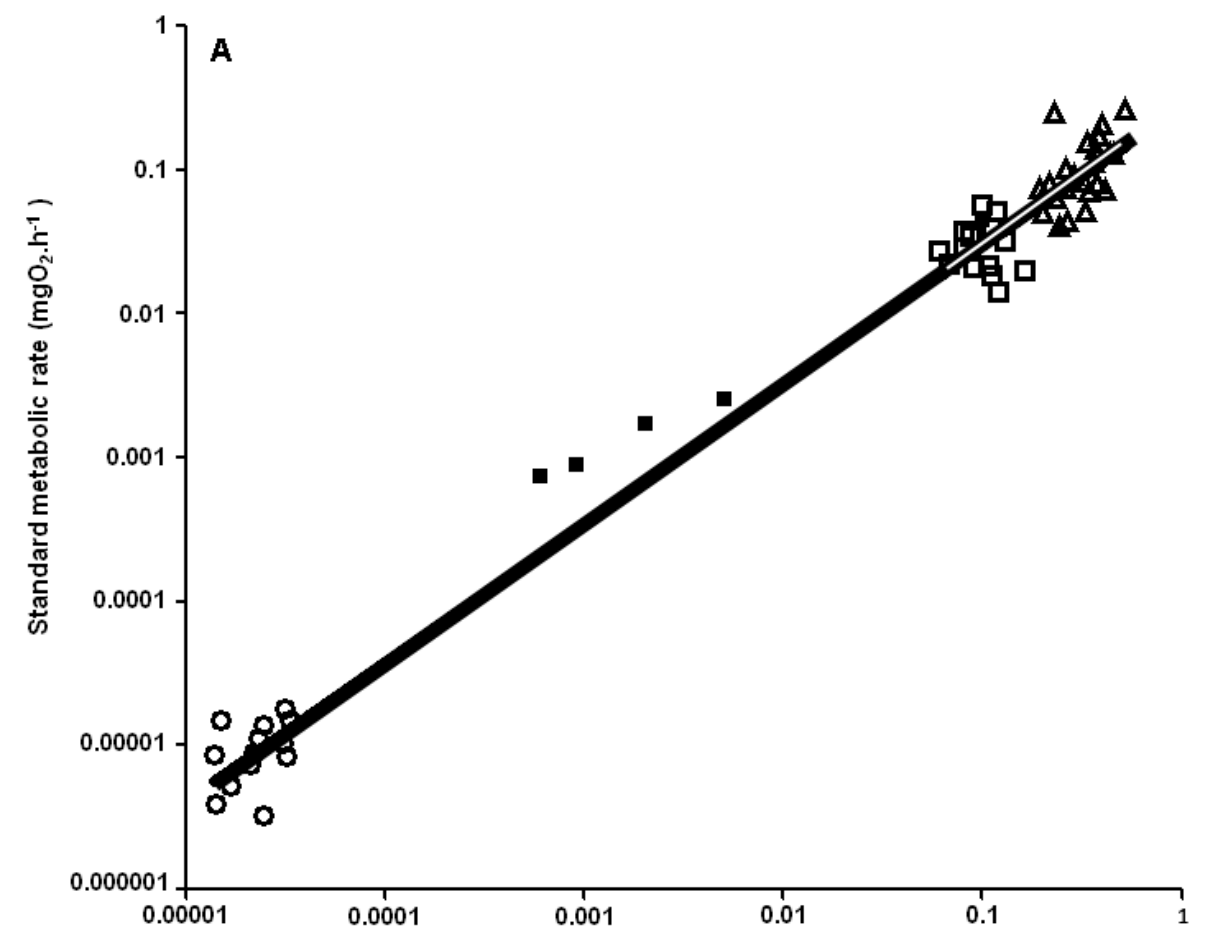




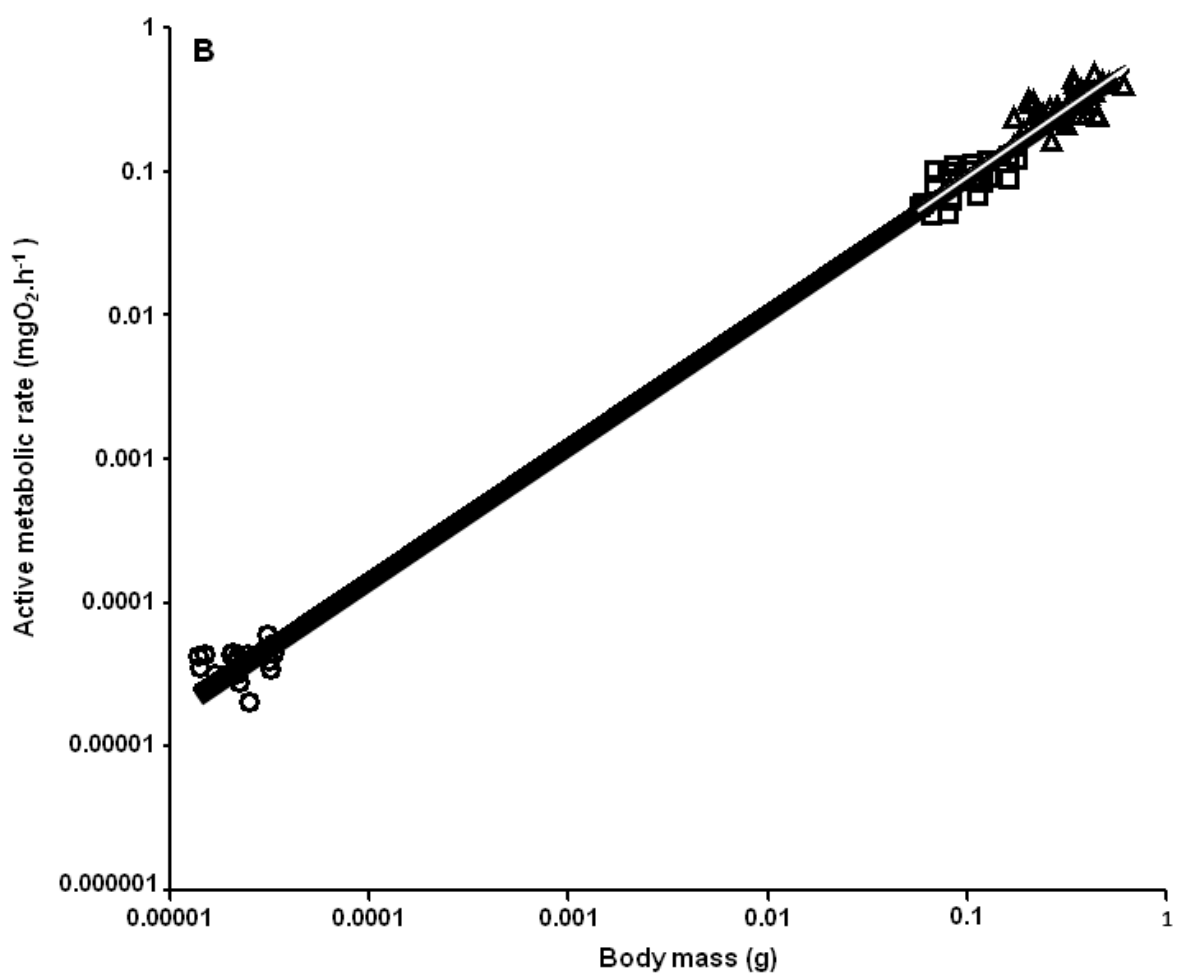

182 FIG. 1. Relationships between aerobic metabolic rate and body mass for D. rerio. On each graph, the black line 183 represents the scaling relationship across the three life stages: 5 day-old larvae ( $\bigcirc, L), 2$ month-old juveniles ( $\square$, $184 \mathrm{~J})$ and 6 month-old adults $(\triangle, A)$. The white line shows the scaling only for juveniles and adults $(J+A)$. The 185 scaling factor $a$ and scaling exponent $b$ were estimated through the allometric equation $R=a M^{b}($ equation 2$)$. For 186 each of these constants, the value is expressed as the average ( \pm standard error). For standard metabolic rate

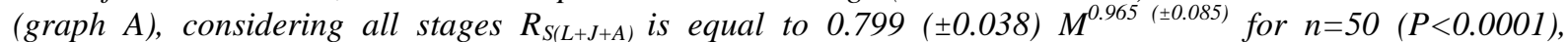
considering juveniles and adults, $R_{A(J+A)}$ is equal to $0.809( \pm 0.084) M^{0.969( \pm 0.110)}$ for $n=37(P<0.0001)$. Regarding active metabolic rate $($ graph $B): R_{A(L+J+A)} 0.273( \pm 0.024) M^{0.926( \pm 0.010)}$ for $n=78 \quad(P<0.0001), \quad R_{A(J+A)}$ $0.276( \pm 0.051) M^{0.931( \pm 0.068)}$ for $n=60(P<0.0001)$. In addition, the studies of Barrionuevo\&Burggren (1999) and Burggren (2005) measured oxygen consumption in fish presenting a resting state at the temperature of $28^{\circ} \mathrm{C}$ which permitted to complete our data set regarding the standard metabolic rate at the same temperature. After conversion into $\mathrm{mgO}_{2} \cdot h^{-1}$, these values were added on the graph $(A, \mathbf{\square})$.

196 This is the first study examining the scaling of metabolic rate with body mass over the

197 lifecycle of D.rerio. The results indicate that a single scaling exponent can be employed

198 irrespective of life stgae in this species. This is in agreement with the observations made by

199 Killen et al.(2007) on three species of marine teleost (e.g. ocean

200 poutMacrozoarcesamericanusBloch \& Schneider 1801; lumpfish Cyclopteruslumpu,sL. 1758;

201 and shorthorn sculpinMyoxocephalusscorpius, L. 1758), while the contrary was shown by 
Post \& Lee (1996) for other species (e.g. the common carp Cyprinus carpi, L. 1758; rainbow 203 trout Oncorhynchusmykis, Walbaum 1792; sea bream Pagrusmajo, Temmink\& Schlegel 204 1843). White \& Seymour (2011) studied mass-specific $R_{\mathrm{S}}$ of 31 fish species and reported that several species have higher allometric exponents in early larval stages compared to their later stages. Also, in their study of yellowtail kingfish Seriolalalandi (Valenciennes 1833), Moran 207 \& Wells (2007) considered that the allometric exponent changed continually during 208 development. In fact, metabolism in larvae may be affected by processes specific to this early ontogenic stage such as higher rates of protein turnover, development of energy consuming tissue or organs, or the progressive transition from cutaneous gas exchange to branchial 211 respiration or changes in swimming ability (Post \& Lee, 1996; Killenet al., 2007; White \& 212 Seymour, 2011; Gore \&Burggren, 2012).Nontheless, understanding of ontogenic changes in 213 aerobic scope in fishes throughout remains limited. In D. rerio, the general pattern observed 214 may be related to its short lifecycle, 5dpf larvae having already completed most of their 215 organogenesis (Kimmel et al., 1995). It could be interesting to obtain data for 21dpf, when 216 larval metamorphosis occurs with maturation of several physiological functions and the 217 completion of the transfer of respiratory gas exchange from predominantly cutaneous to 218 predominantly branchial.

219 As expected, the scaling exponents $b_{R A}$ and $b_{R S}$ differed significantly from 1 , confirming that 220 metabolic rate scaled allometrically with body mass in this species (Student's t-test, $221 \mathrm{t}_{1.47}=55.88, \mathrm{P}<0.0001$ for $\mathrm{b}_{\mathrm{RA}} ; \mathrm{t}_{1.47}=5.224, \mathrm{P}<0.05$ for $\left.\mathrm{b}_{\mathrm{RS}}\right)$.

222 Although studies by Kleiber (1932) on mammals and Hemmingsen (1960) onunicells, 223 multicellular ectotherms and endotherms suggested that 0.75 was a universal scaling exponent, recent investigations on fishes have revealed significant heterogeneity in scaling exponents among species (Glazier, 2005, 2006, 2009c; White et al., 2006; Downs et al., 2008; White, 2011).Among the teleosts, several studies have found that the scaling exponent of 
metabolic rate differed from 0.75 (Post \& Lee 1996; Clark \& Johnston, 1999; Bokma, 2004;

228 Peck, 2004), which is in agreement with the present results. It is worth noticing that a lot of scaling studies in teleosts are based on routine or "resting" metabolic rate, rather than $R_{\mathrm{S}}$ or $R_{\mathrm{A}}$. This is not directly comparable with the present results, but illustrates the interspecific

232 found a scaling exponent of 0.90 forS. lalandi. Bokma (2004) examined intraspecific 233 allometry for the sea trout Salmotrutatruta in various life stages and found $\mathrm{b}_{R M R}$ to be 0.86 . 234 Indeed, lifestyle, swimming mode and environmental characteristics of the habitat are all 235 known to modify metabolic rate, as well as the scaling exponent in fishes (Killen et al., 2007, 236 2010). Previous studies have also found that $b_{R A}$ was significantly different from $b_{R S}$ (Brett \& 237 Glass, 1973; Weiser, 1985; Weibelet al., 2004; Killen et al., 2007), and this was true in D. 238 rerio (Student's t-test $\left.\mathrm{t}_{1.94}=4.475, \mathrm{P}<0.05\right)$, which is also suggested by several studies. 239 However, $b_{R A}$ generallytends to be higher than $b_{R S}$ (Weibelet al., 2004; Killenet al., 2007) 240 while the opposite was observed in D. rerio, where $b_{R A}<b_{R S}$. This may, at least in part, reflect 241 the fact that D. rerio is a domesticated species that has been reared in laboratory for many 242 generations, whereas the study by Killenet al. (2007) was on individuals captured in wild.

243 In conclusion, this study estimated the scaling exponent $\mathrm{b}$ across three life stages of $D$. rerio 244 (5 dpf to 6 month old fish). This provides a basis for further experiments regarding the effects 245 of environmental factors on aerobic metabolismin this species.

247 The authors thank Didier Leguay and Michel Prineau, for their help during the experiment. 248 All experiments were carried out at Ifremer (Plateformed'Ecophysiologie des Poissons), La 249 Rochelle station, France.This study was financially supported by the ANR project 250 ConPhyPoP (CES 09_002) and JL received a doctoral grant of the Regional Council of 
251 Poitou-Charentes. This study was conducted under the approval of Animal Care Committee of

252 France under the official licence of Marie-Laure Bégout (17-010).

\section{References}

Barrionuevo, W. R. \& Burggren. W. W. (1999). O2 consumption and heart rate in developing zebrafish (Daniorerio): influence of temperature and ambient O2. American Journal of Physiology276, 505-513.

Bokma, F.(2004). Evidence against universal metabolic allometry.Functional Ecology18, $261 \quad 184-187$.

Brett, J. R. (1964). The respiratory metabolism and swimming performance of young sockeye salmon.Canadian Journal of Fisheries and Aquatic Sciences5, 1183-1226.

Brett, J. R. \& Glass, N. R. (1973).Metabolic rates and critical swim speeds of sockeye salmon (Oncorhynchusnerka).Canadian Journal of Fisheries Research30, 379-387.

Burggren, W. W. (2005). Developing animals flout prominent assumptions of ecological physiology. Comparative Biochemistry and Physiology, Part A 141, 430 - 439.

272 Cannas, M., Atzori, F., Rupsard, F., Bustamante, P., Loizeau, V., Lefrançois, C. (2012). PCB contamination does not alter aerobic metabolism and tolerance to hypoxia of juvenile sole 
Claireaux, G. \&Lefrançois, C. (2007). Linking environmental variability and fish 277 performance: integration through the concept of metabolic scope for activity. Philosophical Transactions of the Royal Society of London series B: Biological Sciences. 362, 2031-2041.

Clark, T. D., Donaldson, M. R., Pieperhoff, S., Drenner, S. M., Lotto, A., Cooke, S. J., Hinch,

S. G., Patterson, D. A. \& Farrell, A. P. (2012). Physiological benefits of being small in a changing world: responses of Coho salmon (Oncorhynchuskisutch) to an acute thermal challenge and a simulated capture event. PLOS ONE 7, e39079

Clarke, A. \& Johnston, N. M. (1999). Scaling of metabolic rate with body mass and temperature in teleost fish. Journal of Animal Ecology68, 893-905.

Downs, C. J., Hayes, J. P. \& Tracy, C. R. (2008). Scaling metabolic rate with body mass and inverse body temperature: a test of the Arrhenius fractal supply model. Functional Ecology22, $239-244$.

Fry, F. E. J. (1947). The effects of the environment on animal activity.University of Toronto studies.Biological series55, 1-62.

Fry, F.E.J. (1971). The effect of environmental factors on the physiology of fish. In Fish Physiology Vol. VI (Hoar, W.S., Randall, D.J.,eds.), pp. 1-98. New York, CA:Academic 297 Press. scaling of metabolic rate in animals. Biology Reviews80, 611-662. 
302 Glazier, D. S. (2006). The 3/4-power law is not universal: evolution of isometric, ontogenetic 303 metabolic scaling in pelagic animals. BioScience56, 325-332.

304

305 Glazier, D. S. (2009c). Ontogenetic body-mass scaling of resting metabolic rate covaries with 306 species-specific metabolic level and body size in spiders and snakes. Comparative 307 Biochemistry And Physiology - Part A153, 403-407.

308

309 Gore, M.\&Burggren, W. W. (2012). Cardiac and metabolic physiology of early larval 310 zebrafish (Daniorerio) reflects parental swimming stamina. Frontiers in Aquatic Physiology, $3113-35$.

Hemmingsen, A. M. (1960). Energy metabolism as related to body size and respiratory 314 surfaces, and its evolution.Report of the Steno Memorial Hospital Nordisk 315 Insulinlaboratorium $9,1-110$.

317 Johansen, J. L. \& Jones, G. P. (2011). Increasing ocean temperature reduces the metabolic 318 performance and swimming ability of coral reef damselfishes. Global Change Biology17, $319 \quad 2971-2979$.

321 Jourdan-Pineau, H., Dupont-Prinet, A., Claireaux, G. \& McKenzie, D. J. (2010). An 322 investigation of metabolic prioritization in the European Sea Bass, 323 Dicentrarchuslabrax.Physiological and Biochemical Zoology83(1), 68-77. 
325 Killen, S. S., Costa, I., Brown, J. A. \&Gamperl, A. K. (2007). Little left in the tank: metabolic 326 scaling in marine teleosts and its implications for aerobic scope. Proceeding of the Royal 327 Society B274, 431-438.

329 Killen, S. S., Atkinson, D. \& Glazier, D. S. (2010). The intraspecific scaling of metabolic rate 330 with body mass in fishes depends on lifestyle and temperature. Ecology Letters 13, 184-193.

332 Kimmel, C. B., Ballard, W. W., Kimmel, S. R., Ullmann, B. \& Schilling, T. F. (1995).Stages

333 of Embryonic Development of the Zebrafish.Developmental dynamics203, 253-310.

335 Kleiber, M.(1932). Body size and metabolism.Hilgardia6, 315-353.

Lefrançois, C.\&Claireaux, G. (2003).Influence of ambient oxygenation and temperature on 338 metabolic scope and scope for heart rate in the common sole Soleasolea. Journal of 339 Experimental Biology259, 273-284.

341 Lawrence,C. (2007). The husbandry of zebrafish (Daniorerio): A review. Aquaculture269, 134220.

344 Marit, J. S.\& Weber, L. P. (2011). Acute exposure to 2,4-dinitrophenol alters zebrafish 345 swimming performance and whole body triglyceride levels. Comparative Biochemistry and 346 Physiology - Part C 154, 14-18. 
348 Marit, J. S.\& Weber, L. P. (2012).Persistent effects on adult swim performance and energetics

349 in zebrafishdevelopmentally exposed to 2,3,7,8-tetrachlorodibenzo-p-dioxin. Aquatic 350 Toxicology106, 131-139.

352 Miklosi, A. \& Andrew, R. J. (2006).The Zebrafish as a Model for Behavioral Studies. 353 Zebrafish3, 227-234.

354

355 Moran, D. \& Wells, R. M. G. (2007).Ontogenetic scaling of fish metabolism in the mouse-to356 elephant mass magnitude range.Comparative Biochemistry and Physiology - Part A148, 611357620.

358

359 Peck, A., Clemmensen, C. \& Herrmann, J. P. (2005). Ontogenic changes in the allometric 360 scaling of the mass and length relationship in Sprattussprattus. Journal of Fish Biology66, $361 \quad 882-887$.

363 Plaut, I. \& Gordon, M. S. (1994). Swimming metabolism of wild-type and cloned 364 zebrafishBrachydaniorerio. Journal of Experimental Biology194, 209-223.

366 Plaut, I. (2000). Effects of fins size on swimming performance, swimming behaviour and 367 routine activity of zebrafishDaniorerio. Journal of Experimental Biology203, 813-820.

369 Post, J. R. \& Lee, J. A. (1996).Metabolic ontogeny of teleost fishes.Canadian Journal of $370 \quad$ Fisheries and Aquatic Sciences53, 910-923. 
372 Priede, I. G. (1985). Metabolic scope in fish. In: Fish energetics: new Perspectives( Tyler P.

373 \&Calow P., eds), pp. 33-64. London, UK:.Croom Helm.

374

375 Schurmann, H. \&Steffensen, J. F. (1997). Effects of temperature, hypoxia and activity on the 376 metabolism of juvenile Atlantic cod.Journal of Fish Biology50, 1166-1180.

378 Steffensen, J.F.(1989). Some errors in respirometry of aquatic breathers: how to avoid and 379 correct for them. Fish Physiology and Biochemistry6, 49-59

Steffensen, J. F., Bushnell, P. G. \&Schurmann, H. (1994). Oxygen consumption in four 382 species of teleosts from Greenland: no evidence of metabolic cold adaptation. Polar 383 Biology14, 49-54.

Weibel, E. R., Bacigalupe, L. D., Schmidt, B. \&Hoppeler, H. (2004). Allometric scaling of maximal metabolic rate inmammals: muscle aerobic capacity as determinant factor.Respiratory Physiology \& Neurobiology140, 115-132.

Weiser,W. (1985). Developmental and metabolic constraints of the scope for activity in young rainbow trout (Salmogairdneri ). Journal of Experimental Biology118, 133-142.

392 White, C .R., Phillips, N. F. \& Seymour, R. S. (2006).The scaling and temperature 393 dependence of vertebrate metabolism. Biology Letters, 2, 125-127.

395 White, C. R. (2011). Allometric estimation of metabolic rates in animals.Comparative 396 Biochemistry and Physiology - Part A158, 346-357. 
398 White, C. R. \& Seymour, R. S. (2011). Physiological functions that scale to body mass in fish.

399 In Encyclopedia of Fish Physiology: FromGenome to Environment, vol. 3 (A. P. Farrell, eds), 400 pp. 1573-1582. San Diego, Academic Press

401

402 Zar, J. H. (1984) Biostatistical analysis, 2nd edn.Prentice Hall, New Jersey

403

404

405

406 